\title{
Tinjauan Etika: Dokter sebagai Eksekutor Hukuman Pidana yang Menyebabkan Kematian, Kecacatan, atau Gangguan Kesehatan
}

\author{
Soetedjo $^{\mathrm{I}, 2}$, Julitasari Soendoro ${ }^{\mathrm{I}, 3}$, Pukovisa Prawiroharjo ${ }^{\mathrm{I}, 4}$ \\ ${ }^{1}$ Majelis Kehormatan Etik Kedokteran Pengurus Besar Ikatan Dokter Indonesia \\ ${ }^{2}$ Departemen Neurologi, Rumah Sakit Umum Daerah Dr. Moewardi, Surakarta, Jawa Tengah \\ ${ }_{3}^{3}$ The Indonesian Technical Advisory Group on Immunization Communicable Disease Control (ITAGI CDC) \\ ${ }_{4}^{4}$ Departemen Neurologi, Fakultas Kedokteran Universitas Indonesia/Rumah Sakit Cipto Mangunkusumo, Jakarta
}

\author{
Kata Kunci \\ etika kedokteran; eksekutor hukuman pida- \\ na; injeksi letal \\ Korespondensi \\ pukovisa@ui.ac.id \\ contact@ilmiah.id \\ Publikasi \\ (C) $2017 \mathrm{JEKI} /$ ilmiah.id \\ DOI \\ I0.26880/jeki.viiI.5 \\ Tanggal masuk: 9 Juli 2017 \\ Tanggal ditelaah: 25 Juli 2017 \\ Tanggal diterima: 16 Agustus 2017 \\ Tanggal publikasi: II Oktober 2017
}

Abstrak Perkembangan pesat di bidang hukum dan kedokteran di Indonesia menyebabkan wacana akan hukuman pidana berbasis medis tak dapat dikekang lagi. Misalnya injeksi letal, yang dinilai memiliki letalitas tinggi dan bahkan dianggap meminimalisasi penderitaan terpidana, dinilai lebih baik dan etis dibandingkan alternatif eksekusi konvensional seperti hukuman tembak mati. Namun, secara teknis pelaksanaan tindakan pro justitia ini memunculkan dilema etik bagi profesi kedokteran jika tindakan ini mencederai, membuat cacat baik permanen maupun sementara, ataupun menyebabkan kematian bagi terpidana. Di satu sisi, profesi kedokteran senantiasa harus setia pada karakternya yang mengedepankan kemanusiaan dan berorientasi menyembuhkan manusia. Di sisi lain, menyerahkan suatu tindakan kedokteran pro justitia kepada selain dokter, berpotensi merugikan terpidana karena tindakan tersebut tidak dilakukan secara profesional. Dilema etik ini secara umum perlu diatur dalam fatwa etik profesi kedokteran, yang mana merupakan wewenang Majelis Kehormatan Etik Kedokteran (MKEK). Dalam pelaksanaannya, hal ini perlu dimusyawarahkan seluruh pihak yang berkepentingan, termasuk eksekutif, legislatif, dan yudikatif yang akan menarasikan bentuk eksekusi hukuman tersebut.

\begin{abstract}
The rapid development of law and medicine in Indonesia has rendered discourses of medical punishment unrestrained. Lethal injection, for example, which is considered as having high lethality and even minimizing the suffering of convicts, is considered better and more ethical than conventional execution alternatives such as death penalty. However, technically the implementation of this pro justitia action raises the ethical dilemma for medical profession when it harms, makes permanent or temporary disabilities, or causes death to the convicts. On one side, the medical profession must always be faithful to its humanity-oriented, human-oriented character. On the other hand, handing a medical act of pro justitia to other professions potentially harms the convicts due to the action is not performed professionally. This ethical dilemma has to be regulated in a medical profession ethical decree, which is in the authority of the Medical Ethics Council of Honor. In practice, this matter has to be discussed by all interested parties, including the executive, legislative and judiciary who will sentence the form of execution.
\end{abstract}

\section{PENDAHULUAN}

Tuntutan negara dan aparat hukum akan peran tenaga kesehatan dalam mengeksekusi hukuman pidana - yang tentunya berpotensi menyebabkan gangguan kesehatan - telah memicu perdebatan konflik etis yang dihadapi tenaga kesehatan, termasuk profesi kedokteran. Tuntutan ini didasari oleh perkembangan sains dan teknologi, yang memungkinkan perkembangan berbagai metode hukuman pidana atas dasar ilmu kedokteran. Hukuman pidana tersebut seringkali berpotensi menyebabkan gangguan kesehatan, seperti injeksi bahan kimia yang dapat menyebabkan kecacatan atau kematian. Kehadiran tenaga kesehatan (dokter) dalam hal ini dianggap mampu bertindak manusiawi, mengurangi rasa sakit dan memberikan ketenangan bagi terpidana yang akan menjalani hukuman. Seluruh dunia, termasuk Indonesia, memerlukan berbagai terobosan metode eksekusi seiring dengan upaya meningkatkan efek jera, menghindarkan masalah sosial, serta memecahkan masalah kelebihan kapasitas penjara. Variasi metode juga terus dikembangkan untuk bentuk hukuman mati, sehingga menghindarkan orang yang dieksekusi dari penderitaan yang tidak manusiawi, namun tetap mencapai tujuan hukuman yaitu mengakhiri nyawa sang terpidana. Variasi metode juga dikembangkan untuk meningkatkan efek jera, misalnya metode pengebirian bagi pelaku tindak kejahatan seksual berat dan kejahatan seksual di bawah umur. Upaya mencari variasi metode ini tentu saja akan bersinggungan dengan berbagai bidang ilmu, termasuk di antaranya kedokteran, 
sebagai bidang ilmu yang dianggap paling memahami proses biologi dan dampak biologis dari suatu perlakuan atau zat kepada manusia.

Selain sebagai eksekutor hukuman pidana, dokter juga memiliki berbagai peran dalam proses peradilan kriminal, seperti menentukan kompetensi terpidana untuk menjalani persidangan dan memberikan pengobatan bagi narapidana, terutama bagi yang memiliki gangguaan kejiwaan. Walaupun dalam hal ini dokter bermaksud untuk menyembuhkan pasien dengan gangguan jiwa, kesembuhan tersebut justru membuat narapidana dapat dijatuhi hukuman pidana yang telah diputuskan hakim, termasuk hukuman mati.

Fenomena ini menggambarkan adanya loyalitas ganda pada profesi kedokteran, yang mana tak hanya dituntut untuk memprioritaskan kesehatan pasien, tetapi juga dituntut untuk melayani masyarakat, termasuk dengan menjalankan keputusan hukum yang ditujukan untuk kebaikan masyarakat luas. Sebagai profesi dengan kompetensi terbaik untuk menyembuhkan penyakit, apakah ilmu dan keahlian tersebut dapat digunakan untuk hal sebaliknya? Bagaimanakah dasar etika kedokteran dalam menghargai keputusan hukum? Untuk menjawab pertanyaan-pertanyaan tersebut, tulisan ini hendak meninjau etika kedokteran sebagai eksekutor hukuman pidana yang menyebabkan gangguan kesehatan, kecacatan dan risiko kesehatan lainnya.

\section{METODE}

Penelusuran literatur dilakukan melalui database jurnal etik kedokteran dan biomedis, seperti PubMed, New England Journal of Medicine, dan Canadian Medical Association Journal. Sistem pencari Google Scholar juga digunakan untuk mencari literatur tambahan dari sumber terpercaya, termasuk berbagai situs resmi dari organisasi profesi atau publikasi pemerintah. Kata kunci yang digunakan adalah "etika kedokteran", "eksekutor hukuman pidana”, "injeksi letal”, "hukum kebiri”, dan "Majelis Kedokteran Etik Kedokteran" baik dalam bahasa Inggris maupun Indonesia.

\section{HASIL DAN PEMBAHASAN}

\footnotetext{
Mengapa Dokter Dibutuhkan Dalam Eksekusi Hukuman Pidana yang Menyebabkan Kematian, Kecacatan, atau Gangguan Kesehatan?
}

Di Indonesia, eksekusi hukuman mati masih menggunakan metode hukuman tembak, sebagaimana diatur dalam Penpres No.2/1964 tentang Tata Cara Pelaksanaan Pidana Mati yang Dijatuhkan oleh Pengadilan di Lingkungan Peradilan Umum dan Militer ${ }^{1}$ dan Tata pelaksanaannya diatur dalam Peraturan Kapolri No.12 Tahun 2010 tentang Tata Cara Pelaksanaan Pidana Mati. ${ }^{2}$ Dalam peraturan tersebut, tugas seorang dokter hanya sebatas memberikan kepastian kematian terpidana, yang mana tidak membahayakan pidana sehingga dapat dianggap tidak bertolak belakang dengan etika kedokteran. ${ }^{1,2}$

Namun di Amerika Serikat, peran dokter bukan hanya diharapkan, tetapi menjadi syarat untuk eksekusi hukuman mati di 18 negara bagian di Amerika Serikat, sedangkan 17 negara bagian lainnya tidak mensyaratkan namun memperbolehkan adanya dokter dalam eksekusi hukuman mati. ${ }^{3}$ Hal ini dikarenakan semakin meningkatnya penggunaan injeksi letal sebagai standar prosedur hukuman mati, di mana prosedur tersebut mengandung beberapa elemen dari praktik medis seperti menghitung dosis obat, menyuntikkan obat intravena, dan memonitor tanda-tanda vital. Sejak tahun 1976, 1.280 injeksi letal telah digunakan untuk eksekusi hukuman mati di Amerika Serikat. ${ }^{4}$

Pada umumnya, injeksi letal sendiri terdiri dari tiga fase, yaitu injeksi Sodium thiopental yang memberikan efek anestesi dengan sedasi dan mensupresi pernapasan, Pancuronium bromide (pavulon) yang menyebabkan paralisis otot, dan Potassium chloride yang menyebabkan gagal jantung akut. ${ }^{5}$ Dengan ketidaksadaran diri melalui anestesi dan tidak dapat bergeraknya pidana karena paralisis otot, metode ini menjadi preferensi karena dianggap paling manusiawi dibandingkan metode-metode sebelumnya seperti hukum tembak, gantung, kamar gas, dan kursi listrik. Hukuman tembak dianggap mengakibatkan terlalu banyak keluar darah yang sulit dikontrol, sebagaimana eksekusi hukuman mati Elisio Mares di Utah pada tahun 1951, di mana lima eksekutor menembak tidak tepat sasaran sehingga mengenai dada kanan dan menyebabkannya meninggal perlahan karena perdarahan. ${ }^{6}$ Sedangkan hukum gantung menyebabkan patahnya tulang leher C2 (servikal nomor 2) sehingga pidana mengalami sesak nafas dan baru meninggal setelah beberapa menit. ${ }^{5}$ Metode kamar gas sianida pun menyebabkan kematian yang lebih lama daripada hukum gantung, 
sebagaimanaeksekusihukumanmatiDonald Harding di Arizona pada tahun 1992 yang menyebabkan kematian setelah 11 menit dengan proses yang menyakitkan hingga reporter yang menyaksikan turut menangis. ${ }^{7}$ Walaupun teknik kursi listrik sempat populer digunakan, eksekutor menemukan bahwa seringkali lebih dari satu kali siklus setrum dibutuhkan untuk menyebabkan kematian sehingga menyiksa terpidana yang dieksekusi. ${ }^{6}$

Pada kenyataannya, injeksi letal pun tidak sepenuhnya manusiawi. Thiopental sudah tidak lagi digunakan sebagai anestesi di dunia medis, bahkan kedokteran hewan sekalipun. Hal ini dikarenakan obat tersebut tidak menjamin efek anestesia, sehingga terpidana bisa jadi menderita kesakitan yang berat saat pancuronium bromide diinjeksikan tapi tidak dapat mengekspresikannya karena otot tubuhnya, termasuk pita suara, sudah lumpuh terparalisis. ${ }^{8}$ Risiko tersebut diperparah dengan digantikannya peran dokter oleh "teknisi" seperti phlebotomist, paramedik, atau teknisi medis gawat darurat (Emergency Medical Technician [EMT]), yang tentu memiliki keahlian pada bidang masing-masing, tetapi tidak memiliki pengetahuan yang cukup untuk menghadapi kasus kompleks selayaknya seorang dokter. ${ }^{9}$ Untuk itu, peran dokter, terutama ahli anestesi, dibutuhkan untuk mengeksekusi prosedur yang lebih halus, dengan dosis dan metode administrasi obat yang tepat, serta mampu membuat keputusan medis yang lebih tepat pada kondisi genting, agar mengurangi rasa sakit yang harus dialami narapidana dalam menjalani hukuman mati.

Perlu juga dipahami bahwa dokter yang ikut melaksanakan hukuman pidana tidak dapat secara begitu saja dicap "tidak bermoral". Tujuan dari keikutsertaan mereka bukanlah untuk mengakhiri hidup orang lain atau menimbulkan cacat permanen, tetapi mengurangi penderitaan atau komplikasi dari suatu keputusan hukum yang memang harus dilaksanakan. Sebagai analogi, seorang spesialis bedah dalam melakukan tugasnya juga mencederai pasien, tetapi itu bukan merupakan tujuan dari tindakannya. Tujuan sebenarnya adalah untuk menyembuhkan penyakit pasien. Dengan demikian, tidak seharusnya tindakan seorang dokter dinilai "tidak bermoral" tanpa melihat tujuan akhir dari tindakannya tersebut.

Walaupun peran dokter tidak menimbulkan dilema yang besar pada eksekusi hukuman mati di Indonesia, hukuman lainnya yang menyebabkan kecacatan fungsi masih menjadi suatu perdebatan. Namun, seandainya profesi dokter dilibatkan dalam eksekusi hukuman yang membuat terpidana cacat sementara, maka dokter merupakan profesi yang paling memahami untuk menghindarkan cacat sementara tersebut menjadi permanen dan mengantisipasi efek samping dari tindakan kedokteran yang membuat cacat tersebut. Misalnya, jika eksekusi tersebut adalah dengan pemberian obat-obatan tertentu, maka dokter adalah yang paling memahami mekanisme kerja obat sekaligus dampak klinis dan efek sampingnya terhadap manusia. Dengan demikian, keterlibatan dokter yang memberikan tindakan profesional pro justitia ini mempunyai dasar argumen etis yang kuat, dalam hal dokter bertindak atas nama keadilan tanpa harus mencederai sumpah kedokterannya.

\section{Etika dan Peraturan Perihal Peran Dokter dalam Eksekusi Hukuman Pidana yang Menyebabkan Kematian atau Kecacatan}

Walaupun keberadaan dokter dapat mengurangi risiko sakit yang harus dialami terpidana serta dapat memberikan ketenangan bagi terpidana dan kerabatnya, banyak yang menganggap bahwa hal ini tidak sesuai dengan prinsip dan etika dunia kedokteran. Berdasarkan prinsip etika kedokteran yang terkandung dalam Sumpah Hipokrates, menyebabkan kematian atau kecacatan pada seseorang bertentangan dengan prinsip nonmaleficence atau "do no harm". Kemudian, pidana juga tidak berada dalam situasi yang memperbolehkannya untuk memberikan informed consent atau persetujuan, yang mana merupakan bagian dari prinsip autonomi dalam Sumpah Hipokrates. ${ }^{10}$

Butir nomor lima pada sumpah dokter dalam Kode Etik Kedokteran Indonesia (KODEKI) berbunyi "Saya tidak akan menggunakan pengetahuan dokter saya untuk sesuatu yang bertentangan dengan perikemanusiaan, sekalipun diancam” juga memperkuat dasar agar dokter tidak menggunakan keahliannya untuk menyebabkan kematian atau kecacatan. ${ }^{11}$ Peran dokter di masyarakat yang seharusnya menjadi penyembuh penyakit dan meringankan penderitaan tentu bertolak belakang dengan eksekusi hukuman pidana secara jelas yang mengakibatkan bahaya yang lebih besar daripada keuntungan kepada seorang pasien.

Organisasi profesi kedokteran di Amerika 
Serikat seperti American Medical Association (AMA) melarang campur tangan dokter dalam eksekusi hukuman mati dan hanya memperbolehkan dokter menandatangani sertifikat kematian. ${ }^{12}$ Demikian juga dengan American Board of Anesthesiology (ABA) yang melarang ahli anestesi untuk membantu proses eksekusi hukuman mati. Bagi ahli anestesi yang diketahui membantu proses eksekusi hukuman mati, maka sertifikasi ABA yang dimiliki akan dicabut. ${ }^{13}$ Hal ini menjadi sebuah ancaman yang keras karena kebanyakan rumah sakit tidak mau mempekerjakan ahli anestesi tanpa sertifikasi ABA. Tapi pada sisi lain, peraturan ini sulit dilaksanakan karena aparat penegak hukum dan pemerintah negara bagian berusaha untuk merahasiakan identitas dokter yang membantu. ${ }^{14}$ Sedangkan ancaman AMA untuk mengeluarkan dokter yang membantu proses eksekusi hukuman mati dari keanggotaan AMA tidak memberikan efek yang signifikan karena hanya 15\% dokter di Amerika Serikat yang menjadi anggota organisasi tersebut pada tahun 2011.15 Terlebih lagi, sebuah survey pada tahun 2011 melaporkan bahwa hanya 3\% dari dokter yang menjalani survey mengetahui tentang regulasi tersebut, dan $41 \%$ mengindikasikan bahwa mereka bersedia melakukan setidaknya salah satu kegiatan yang dilarang oleh AMA. ${ }^{16}$ Walaupun setiap dokter memiliki prinsip dan kepercayaan masing-masing terhadap eksekusi hukuman mati, kode etik AMA menyatakan bahwa seorang dokter bertugas untuk memperpanjang hidup pada situasi hingga batas kemampuannya, sehingga tidak diperbolehkan menjadi bagian dari eksekusi kematian yang legal.12 Dengan demikian, sebagaimana profesi lainnya, setiap dokter berhak memiliki pendirian pribadi terhadap suatu hal; tetapi ketika situasi tersebut membutuhkan keahliannya sebagai seorang dokter, maka kode etik profesi tetap berlaku baginya Terlebih lagi, peran dokter dalam eksekusi hukuman yang menyebabkan kematian atau kecacatan menjadikan proses tersebut sebagai bagian dari prosedur medis. Hal ini dapat berdampak buruk kepada pelayanan kesehatan dalam situasi seharihari. Contohnya, dengan penggunaan anestesi pada hukuman mati, seorang pasien yang memasuki ruang operasi atau hendak menjalani prosedur dengan anestesi cenderung mengasosiasikan prosedur medis tersebut dengan eksekusi kematian. Dengan ini, kepercayaan publik terhadap dunia kedokteran pun dapat menurun. Di samping itu, ketika pasien yang dilayani dokter adalah seorang narapidana, maka akan semakin sulit antara keduanya untuk membangunkepercayaan. Halinidikarenakanadanya potensi anggapan dari narapidana, bahwa motif dokter mengobatinya adalah agar kesembuhannya menjadikan narapidana tersebut kompeten untuk menjalani eksekusi hukuman pidana. Maka dokter pun akan semakin sulit dalam menjalankan tugasnya dalam menyembuhkan pasien, baik bagi pasien berstatus narapidana maupun masyarakat umum.

\section{KESIMPULAN}

Menyembuhkan penyakit dan meringankan rasa sakit merupakan tanggung jawab utama seorang dokter terhadap ilmu yang telah ia peroleh semasa studinya. Namun, perkembangan dunia kedokteran telah menciptakan makna yang lebih besar akan tanggung jawab seorang dokter, yang mana tak hanya untuk pasien, tetapi terkadang juga untuk hukum dan publik. Pada akhirnya, dapat diambil kesimpulan bahwa diperlukan usaha untuk mencari solusi baik dari sisi hukum maupun dunia kedokteran. Aparat hukum dan pemerintah diharapkan mendapat pemahaman komprehensif dalam membuat regulasi yang lebih ketat akan perlunya pertimbangan dalam pelaksanaan hukuman pidana, sesuai dengan keputusan hakim dan etika kedokteran yang berlaku. Etika dan prinsip profesi kedokteran serta nilai-nilai hak asasi manusia (HAM) perlu ditanamkan dalam pendidikan kedokteran sejak dini. Dengan demikian, tidaklah sulit untuk organisasi profesi bekerjasama dengan aparat penegak hukum dan negara dalam membuat aturan pelaksanaan regulasi yang lebih akomodatif guna tercapainya tujuan pemberian hukuman pidana. Maka, profesi dokter dapat tetap menaruh hormat pada ketentuan hukum yang berlaku dan membantunya menyelesaikan masalah hukum, tanpa harus mencederai sumpahnya.

\section{KONFLIK KEPENTINGAN}

Tidak ada konflik kepentingan.

\section{REFERENSI}

1. Penetapan Presiden Republik Indonesia nomor 2 tahun 1964 tentang tata-cara pelaksanaan pidana mati yang dijatuhkan oleh pengadilan 
di lingkungan peradilan umum dan militer. 1964. Diunduh dari: http://peraturan.go.id/ penpres/nomor-2-tahun-1964-11e44c4e306287708 8f9313231323233.html

2. Peraturan Kepala Kepolisian Negara Republik Indonesia nomor 12 tahun 2010 tentang tata cara pelaksanaan pidana mati. 2010. Diunduh dari: http://ditlantas.sumut.polri.go.id/main/ show-attachment/50

3. Black L, Sade RM. Lethal injection and physicians. JAMA J Am Med Assoc. 2007;298(23):2779.

4. Death Penalty Information Center. Facts about death penalty [Internet]. 2017 Aug 25. Diunduh dari: https://deathpenaltyinfo.org/ documents/FactSheet.pdf

5. Gawande A. When law and ethics collide - why physicians participate in executions. New Engl J Med. 2006;354(23):1221-9. doi: 10.1056/ NEJMp068042.

6. Trombley S. The execution protocol: Inside America's capital punishment industry. New York: Crown; 1992.

7. Solotaroff I. The last face you'll ever See: The private life of the American death penalty. New York: Harper Collins; 2010.

8. Wilbur R. Doctors shouldn't kill people [Internet]. 2010 Oct [disitasi 2017 Aug 2].

Diunduh dari: http://www.nodeathpenalty.org/ new_abolitionist/october-2010-issue-52/doctorsshouldnt-kill-people

9. Sawicki NN. Doctors, discipline, and the death penalty: Professional implications of safe harbor policies. Yale Law Policy Rev. 2008;27(1):107-72.

10. John Hopkins Sheridan Librarian. Guides: Bioethics: Hippocratic Oath [Internet]. 2017 [disitasi 2017 Aug 2]. Diunduh dari: http://guides. library.jhu.edu/c.php?g=202502\&p=1335759

11. Majelis Kehormatan Etik Kedokteran Indonesia. Kode etik kedokteran Indonesia dan pedoman pelaksanaan kode etik kedokteran Indonesia. Jakarta; 2002.

12. American Medical Association. Ethical opinion E-2.06: Capital punishment. In: Code of medical ethics of the American Medical Association 2006-2007 ed. Chicago: American Medical Association; 2006. p. 19-20.

13. The American Board of Anesthesiology. Anesthesiologists and capital punishment [Internet]. 2014 May [disitasi 2017 Aug 2]. Diunduh dari: http://www.theaba.org/PDFs/BOI/ CapitalPunishmentCommentary

14. Wilbur R. Practicing medicine on death row [Internet]. 2010 Dec 9 [disitasi 2017 Aug 2]. Diunduh dari: http://truth-out.org/archive/ component/k2/item/93256:practicing-medicineon-death-row

15. Collier R. American Medical Association membership woes continue. CMAJ. 2011;183(11). doi: 10.1503/cmaj.109-3943.

16. Donohoe M. Doctors gone bad: Human subject experimentation (WW II - present) torturers, murderers, and despots [Internet]. Public Health and Social Justice. 2017. Diunduh dari: https://phsj.org/wp-content/uploads/2016/09/ Human-Subject-Experimentation-Nazis-Present.ppt 